\title{
Production of Prebiotic Functional Shrimp Nuggets Using ß-Glucan and Reduction of Oil Absorption by Carboxymethyl Cellulose: Impacts on Sensory and Physical Properties
}

\author{
Mehrdad Haghshenas ${ }^{1}$, Hedayat Hosseini' ${ }^{1 *}$, Kooshan Nayebzadeh ${ }^{1}$, Amin Mousavi Khaneghah ${ }^{2}$, Behnoosh Shabkoohi Kakesh ${ }^{1}$ and Rozita \\ Komeily Fonood ${ }^{1}$
}

${ }^{1}$ Department of Food Sciences and Technology, National Nutrition and Food Technology Research Institute, Faculty of Nutrition and Food Technology, Shahid Beheshti University of Medical Sciences, Tehran, Iran

${ }^{2}$ Department of Food Science, Faculty of Food Engineering, State University of Campinas (UNICAMP), São Paulo, Brazil

\begin{abstract}
In recent years consumer demand for healthier foods such as seafood products possessing appropriate functional properties and low calories has been increased. In this study, shrimp nuggets having functional properties were manufactured by incorporating commercially available ß-glucan and carboxy methyl cellulose (CMC), and were evaluated for sensory, chemical and physical properties. Texture profile analysis (TPA) of par-fried and full fried products showed that shrimp nuggets containing both ß-glucan and carboxy methyl cellulose (BG+CMC formulation) had significantly higher springiness, chewiness and cohesiveness than control $(p<0.05)$ and lower hardness and shear force values. Addition of $1 \% \mathrm{CMC}$ to the batter formulation with $3 \%$ ß-glucan in core reduced $27 \%$ of oil absorption during frying step. Differences in sensory evaluation values between nuggets containing CMC and control were not significant at any particular factors except for the juiciness. Application of BG as a prebiotic soluble fiber and $\mathrm{CMC}$ reduces oil uptake during frying, and provides a functional calorie- reduced sea food product with desirable organoleptic properties.
\end{abstract}

Keywords: Shrimp nuggets; ß-glucan; Carboxymethyl cellulose; Functional food; Physical properties; Sensory evaluation

\section{Introduction}

Nuggets are small batter-fried paste or piece of chicken, fish or shrimp. Consumption of breaded and battered foods especially seafood, poultry, cheese, and vegetables has become popular over the last few years. Shrimp is one of the world's most popular consumed shellfish [1]. They are low in saturated fat and high in omega-3 fatty acids. In addition, shrimps are excellent sources of essential amino acids, iron, zinc, copper, and vitamin B-12; however, they are considered as highly perishable commodities. In this regard, several processing methods have been utilized to increase their shelf life $[2,3]$.

\section{Literature}

Deep-frying is a preservation method to increase shelf life of foods by reducing the moisture content and microbial population. It also provides a unique combination of flavor and texture properties that improve overall characteristics of the food product $[4,5]$. Fried shrimp as a fried and easy-to-eat meal, can be a nutritious food with increased shelf life [6,7]. These products are tender and moist on the inside, and have a porous crunchy crust on the surface that enhances their palatability $[8,9]$. However, during deep-frying a noticeable amount of oil is absorbed in the crust. Now a days, this is often considered to be a negative aspect of deep-fried products that is in contrast with the increasing demand of low-fat foods [10]. Frying affects heat and mass transfer that causes oil moves into the product and water escape from the product into the oil. High temperature causes partial evaporation of water, which moves away from the food and through the surrounding oil. Even though fried foods usually contain high amount of fat, they are still commonly used as popular food products. Global food demand is shifted toward the consumption of low fat and low calories food products to reduce blood cholesterol, hypertension and coronary heart diseases. Several methods are used to reduce oil absorption during deep-fat frying of foods [11]. It is also desirable to minimize moisture loss during frying to maintain textural characteristics of the final fried product [12]. Food coatings proved effective to minimize moisture loss. The effectiveness of coating is explained by its mechanical and barrier properties, which depend on the composition, microstructure and characteristics of the substrate. Among the different approaches to reduce oil absorption during frying, incorporation of hydrocolloids such as cellulose derivatives is suggested [13,14]. A hydrocolloid mixture is usually added to the batter or breading coating to create a barrier against oil absorption either before and/or during frying [1517]. Carboxymethyl cellulose (CMC) is a water-soluble compound with good film-forming properties [18]. Thermal gelation ability of CMC reduces oil absorption and consequently minimizes calorie intake [19]. The effects of battering and breading in enhancing sensory, physical and chemical properties of various nuggets prepared from shrimp, mackerel, meat and chicken are studied [19-23]. Today, the use of $\beta$-glucan due to its functional and nutritional properties is gaining interest. Common oat (Avena sativa) is species of cereal grain mainly grown for its utilization for human consumption. Oat has always been regarded as a health promoting food without clear knowledge of its specific health related effects. It is known for its effects on satiety and retarded absorption of nutrients as well as a deterrent

*Corresponding author: Hedayat Hosseini, Department of Food Sciences and Technology, National Nutrition and Food Technology, Research Institute, Faculty of Nutrition and Food Technology, Shahid Beheshti University of Medical Sciences, Tehran, Iran, Tel: 982122376426; Fax: 982122360660; E-mail: hedayat@sbmu.ac.ir

Received March 18, 2014; Accepted June 28, 2014; Published July 14, 2014

Citation: Haghshenas M, Hosseini H, Nayebzadeh K, Khanghah AM, Kakesh BS et al. (2014) Production of Prebiotic Functional Shrimp Nuggets Using ß-Glucan and Reduction of Oil Absorption by Carboxymethyl Cellulose: Impacts on Sensory and Physical Properties. J Aquac Res Development 5: 245 doi:10.4172/21559546.1000245

Copyright: (C) 2014 Haghshenas M, et al. This is an open-access article distributed under the terms of the Creative Commons Attribution License, which permits unrestricted use, distribution, and reproduction in any medium, provided the original author and source are credited. 
Citation: Haghshenas M, Hosseini H, Nayebzadeh K, Khanghah AM, Kakesh BS, et al. (2014) Production of Prebiotic Functional Shrimp Nuggets Using B-Glucan and Reduction of Oil Absorption by Carboxymethyl Cellulose: Impacts on Sensory and Physical Properties. J Aquac Res Development 5: 245 doi:10.4172/2155-9546.1000245

of various disorders of the gastrointestinal disease [24]. Oat $\beta$-glucan (BG) behaves as a prebiotic, and non-digestible food ingredient that affects the host beneficially by selectively stimulating the growth and/ or activity of one strain or a limited number of bacterial strains in the colon and thus improves host health [25]. In 1997, the U.S. Food and Drug Administration (FDA) approved a health claim for the use of oatbased foods for lowering the risk of heart disease and passed a unique ruling that allowed oat bran to be registered as the first cholesterolreducing food at a dosage of $3 \mathrm{~g} \beta$-glucan per day. Moreover, it is allowed by the FDA to claim health benefits for oat products when $0.75 \mathrm{~g}$ of $\beta$-glucan is consumed in a serving portion. Oat is a rich and economically important source of soluble dietary fiber. It lowers blood cholesterol [26,27] and post prandial glucose level [28], strengthen immune response and reduces the risk of colon cancer [29]. Prebiotic shrimp nuggets using $ß$-glucan can supply up to $1 \mathrm{~g}$ of daily soluble fiber intake [30]; furthermore, when consumed with a diet low saturated fat and cholesterol, it may reduce the risk of heart disease. Although application of prebiotics and reducing oil absorption is known in other foodstuff, it is new for shrimp industry. The main objective of this study was to characterize product and sensory properties of industrial shrimp nuggets supplemented with $\beta$ - glucan and to demonstrate the effect of carboxymethyl cellulose on the oil absorption of the final product.

\section{Materials and Methods}

\section{Preparation of batters and shrimp nuggets}

Four different shrimp nuggets were formulated according to Table 1. A reference batter was prepared by mixing egg powder $(10.4 \%)$ and wheat flour (89.6\%). In batter formula, 1\% carboxymethyl cellulose (SUNROSE ${ }^{\circledR}$, Nippon Paper Industries Co., Ltd., Japan) was added, replacing the same amount of egg powder. High viscosity in batters containing $1 \% \mathrm{CMC}$ is associated with higher pick-up values [31]. The water: dry mixture ratio was kept at 2:1 (w/v) in all the formulations (Venugopal, 2006). The temperature of the water before mixing was $5^{\circ} \mathrm{C}$ Shrimps (Penaeus indicus) were obtained from an aquaculture facility located in Mobarakian, Iran in summer 2012. In BG formula, $3 \%$ bread crumb of nuggets was replaced with $3 \% \beta$-glucan ( $34 \%$ purity, promOat $^{\mathrm{TM}}$, Biovelop International $\mathrm{AB}$, Sweden). It yields about $1 \mathrm{~g}$ of

\begin{tabular}{|l|c|c|c|c|}
\hline Formulation (\%) & C & CMC & BG & CMC+BG \\
\hline Grinded shrimp & 70 & 70 & 70 & 70 \\
\hline Bread crumb & 10.1 & 10.1 & 7.1 & 7.1 \\
\hline Sunflower oil & 4.5 & 4.5 & 4.5 & 4.5 \\
\hline Carboxymethyl cellulose & - & 1 & - & 1 \\
\hline B-glucan & - & - & 3 & 3 \\
\hline Onion & 1.5 & 1.5 & 1.5 & 1.5 \\
\hline Skim milk & 1 & 1 & 1 & 1 \\
\hline Salt & 1 & 1 & 1 & 1 \\
\hline Sodium caseinate & 0.5 & 0.5 & 0.5 & 0.5 \\
\hline Soy isolate & 0.5 & 0.5 & 0.5 & 0.5 \\
\hline Hot pepper flavor & 1 & 1 & 1 & 1 \\
\hline Black Pepper flavor & 0.2 & 0.2 & 0.2 & 0.2 \\
\hline Nutmeg flavor & 0.1 & 0.1 & 0.1 & 0.1 \\
\hline Batter wheat flour & 2.6 & 2.6 & 2.6 & 2.6 \\
\hline Egg powder & 0.3 & 0.27 & 0.27 & 0.27 \\
\hline Water & 4.8 & 4.8 & 4.8 & 4.8 \\
\hline
\end{tabular}

Formulations: Control; CMC Carboxy methyl cellulose $1 \%$ of batter; $3 \% \beta$-glucan in the core of nuggets;

$378 \mathrm{CMC}+\mathrm{BC}$ Carboxy methyl cellulose $1 \%$ of batter and $3 \% \beta$-glucan in the center (core?) of nuggets

Table 1: Different shrimp 366 nugget formulations. $\beta$-glucan per serving portion (90 g) of shrimp nuggets, and provides prebiotic properties [32]. The $\mathrm{CMC}+\mathrm{BG}$ formula was prepared by incorporating $1 \%$ carboxymethyl cellulose in batter and $3 \% \beta$-glucan in the core of nuggets, resulted in $0.27 \%$ egg powder in batter and $7.1 \%$ breadcrumb in core of nuggets. No hydrocolloid was used in control formula. Similar content of ingredients were added to all formulations to make raw nugget paste. The paste was entered to shrimp former and nuggets were shaped. After forming of, pre-dusting, battering and breading were done respectively. Then raw nuggets were fried at $190^{\circ} \mathrm{C}$ for 30 seconds using a continuous fryer (DARIN Continuous frying machine, Model: CF400, China) to make par-fried nuggets. Shrimp nuggets were frozen at $-40 \pm 2{ }^{\circ} \mathrm{C}$ using an Individually Quick Frozen (IQF) technique (CFS Koppens Spiral Freezer, Model: SVR 600, The Netherlands), packaged and stored at $-18^{\circ} \mathrm{C}[33]$.

\section{Frying}

Par-fried shrimp nuggets were deep-fried at $180 \pm 2{ }^{\circ} \mathrm{C}$ for $2 \mathrm{~min}$ in hydrogenated soy bean oil (Pars Ghoo Edible Oil Mfg. Factory Complex, Tehran, Iran) using a 3-L capacity bench-top deep-fat fryer (Delonghi, ROTOFRITEUSE, Italy). Frying temperature was monitored using a temperature controller (model 689000-01, Eutech Instruments Pte Ltd., Singapore). Fresh oil was preheated (stressed) for $2 \mathrm{~h}$ before frying the samples. Shrimp nuggets were deep-fried one by one to minimize temperature fluctuation during frying [34].

\section{Moisture content}

Two grams of homogenized shrimp nuggets were placed onto an aluminum dish (Fisher Scientific Co., Fairlawn, NJ) and dispersed evenly across the dish. The moisture content then determined after drying in the oven for $24 \mathrm{~h}$ at $105^{\circ} \mathrm{C}$ [35].

\section{Fat content}

Fat content of shrimp nuggets was determined using the Soxhlet extraction method (AOAC, 2005). A $5 \mathrm{~g}$ sample was extracted with 10 $\mathrm{ml}$ petroleum ether for $16 \mathrm{~h}$ at a drip rate of approximately $10 \mathrm{~mL} /$ min. Percent fat content was calculated gravimetrically on a dry weight basis.

\section{Warner-Bratzler shear force (WBS)}

Warner-Bratzler shear force in par-fried and full fried shrimp nugget samples was quantified using an Instron Universal Testing machine (Instron Corporation, Rochdale, England) equipped with a $500 \mathrm{~N}$ load cell (Instron Corporation, Rochdale, England). The samples were chopped into cubes $(2 \times 2 \times 2 \mathrm{~cm})$, and then were hooked to the testing machine for the measurement. Each sample was sheared by a $\mathrm{V}$-shaped cutting blade ( $0.9 \mathrm{~mm}$ thickness) at a triangular aperture of $60^{\circ} \mathrm{C}$ and cross head speed of $60 \mathrm{~mm} / \mathrm{min}$ [36].

\section{Texture profile analysis (TPA)}

Textural properties of nuggets were evaluated using a texture analyzer (Stable Micro System, Model TA.XT 2i/25, UK). Texture profile analysis was performed on central cores of five pieces for each sample pieces $(1.5 \mathrm{~cm} \times 1.5 \mathrm{~cm} \times 1.5 \mathrm{~cm})$, which were compressed twice to $80 \%$ of the original height by a compression probe (P 75) at a cross head speed of $2 \mathrm{~mm} / \mathrm{s}$. The following parameters were determined: hardness $\left(\mathrm{N} / \mathrm{cm}^{2}\right)=$ maximum force required to compress the sample $(\mathrm{H})$; springiness $(\mathrm{cm})=$ ability of sample to recover its original form after a deforming force was removed (S); cohesiveness=extent to which sample could be deformed prior to rupture (A2/A1,where A1 is the total energy required for first compression and A2 the total energy 
Citation: Haghshenas M, Hosseini H, Nayebzadeh K, Khanghah AM, Kakesh BS, et al. (2014) Production of Prebiotic Functional Shrimp Nuggets Using B-Glucan and Reduction of Oil Absorption by Carboxymethyl Cellulose: Impacts on Sensory and Physical Properties. J Aquac Res Development 5: 245 doi:10.4172/2155-9546.1000245

Page 3 of 5

required for the second compression); gumminess $\left(\mathrm{N} / \mathrm{cm}^{2}\right)=$ force necessary to disintegrate a semisolid sample for swallowing $(\mathrm{H} \times$ cohesiveness); chewiness $(\mathrm{N} / \mathrm{cm})=$ work to masticate the sample for swallowing (S×gumminess) [37].

\section{Sensory evaluation}

For sensory evaluation, par-fried nuggets were fried and served to 10 trained panelists to assess the color, taste, texture, smell, juiciness, chewiness and overall acceptability of the products using a 9-point hedonic test ( $1=$ dislike extremely, $5=$ neither like nor dislike, and $9=$ like extremely) [25].

\section{Experimental design and statistical methods}

All experiments were performed in three replicates. The SPSS Version 19 Statistical software (SPSS Inc, an IBM Company, Chicago, IL, USA) was used for the statistical analyses. Analysis of variance (ANOVA) was performed and significant differences were calculated at 5\% significant level. Duncan's Multiple Range Test was performed where the ANOVA procedure showed significance. Sensory data were analyzed by a non-parametric test using Kruskal-Wallis test.

\section{Results and Discussion}

\section{Moisture and fat content}

Moisture and fat content of full fried shrimp nuggets (after 3 min frying) are shown in Figure 1. Application of CMC in batter increased the moisture content of the nuggets significantly $(p<0.05)$, which is associated to the ability of CMC to form gel and retain water during frying. There was an inverse relationship between moisture loss and oil uptake $(\mathrm{R} 2=-92.6, \mathrm{p}<0.05)$. Addition of $1 \% \mathrm{CMC}$ to the batter formulation provided $25 \%$ reduction in fat content of nuggets and about $10 \%$ increase in moisture content, as compared with the control formulation. Differences in fat and moisture content between control and CMC formula were significant $(\mathrm{p}<0.05)$ due to the replacement of water with oil following the evaporation process during frying. It was in agreement to the results of another study which used cellulose derivatives coatings to reduce oil uptake in fried products [16]. Using gums in batter formulation resulted in lower oil uptake by enhancing

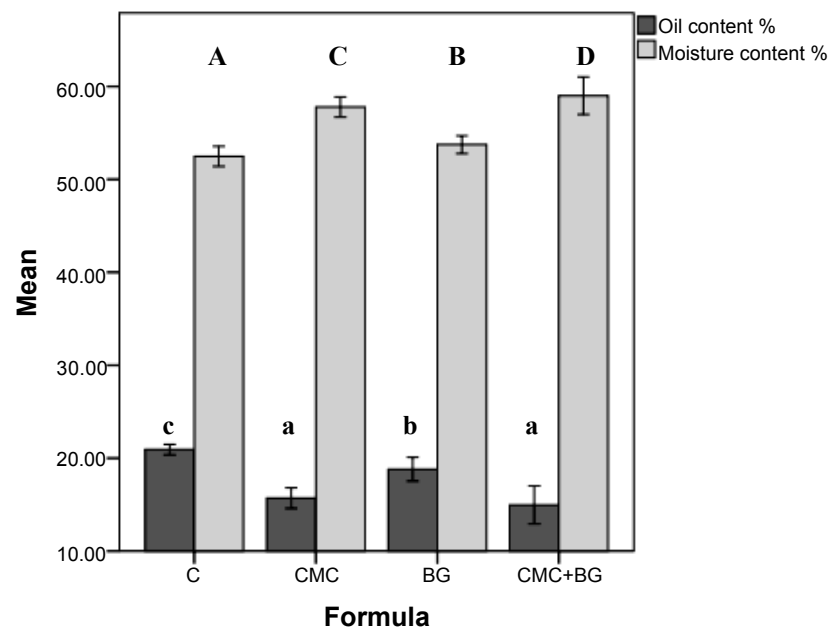

Figure 1: Effect of hydrocolloids on the moisture and oil content of full fried shrimp nuggets Different letters indicate statistical differences between formulations $(p<0.05)$. Small letters are used for oil contentand capital letters for moisture content. retention of moisture caused by the formation of strong hydrogen bonds among water molecules in the batter [19]. In contact with hot oil, CMC forms a gel with high retention capacity that prevents the loss of moisture. Therefore, lower oil absorption is found during the frying process due to the lower moisture loss [16]. Thermal gelation or crosslinking of gums promote the formation of a small amount of wide punctures with low capillary pressures, which reduces the entrance of oil into the pores [4]. The fat content in BG shrimp nuggets was $10 \%$ lower than control $(\mathrm{p}<0.05)$, due to its lower percentages of moisture loss. Compared with the control formulation, BG formula increased the moisture content of nuggets by $5 \%$. An explanation for the lower fat content of BG to control may be due to the protein content of $\beta$-glucan accompanied polysaccharide that increased water-binding capacity and reduced the oil absorption [13-16]. Addition of 1\% CMC to the batter containing 3\% $\beta$-glucan in core formulation showed the least oil absorption (27\% reduction in fat content) and $11.2 \%$ increase in moisture content as compared to the control formula.

Oil and water content of the control and BG+CMC formula were significantly different $(\mathrm{p}<0.05)$. Similar results were observed by Chen and Chen (2009) where in fish nuggets containing 1\% CMC in batter formulation had the highest moisture contents and the lowest oil contents than control [6].

\section{Textural analysis}

Warner-Bratzler shear force and texture profile analyses of par-fried and fully fried nuggets indicated that control sample had significantly $(\mathrm{p}<0.05)$ highest shear force and hardness degree among all formulations (Tables 3 and 4). On the other hand, shear force and hardness degree of nuggets with $\mathrm{CMC}+\mathrm{BG}$ formulation were the least $(\mathrm{p}<0.05)$, which could be due to their higher moisture content. Decreased hardness and shear force in BG par-fried shrimp nuggets could be associated with the impact of protein to polysaccharide ratio that enhanced water-bindingabilities and resulted in a reduced resistance to compression. During heating, the incorporation of a right ratio of $ß$-glucan to meat protein plays an important role in enhancing binding of water molecules in protein, resulting in softer, juicier protein systems which may be desirable in some food products [6-9]. Morin et al. [9] found that sausages containing $\beta$-glucan were softer in texture with increasing levels of, in which $B$-glucanat $0.8 \%(\mathrm{w} / \mathrm{w})$ reduced the compression forces of the product [9]. Springiness of CMC+BG nuggets was significantly higher than other products $(\mathrm{p}<0.05)$, where as the gumminess of $\mathrm{CMC}+\mathrm{BG}$ nuggets, which is directly associated with the hardness, was significantly lower $(\mathrm{p}<0.05)$. Nuggets containing $\mathrm{CMC}$ had significantly higher chewiness and cohesiveness than other formulations $(\mathrm{p}<0.05)$, and $\mathrm{CMC}+\mathrm{BG}$ formula was in the second place.

Thermal gelation property of CMC above its incipient gelation temperature is important in controlling moisture loss [12]. An increased in hardness and shear force of all formula was observed following frying that were due to loss of moisture during the process. Similarly, the springiness of shrimp nuggets was increased in all products after frying process. Like the par-fried shrimp nuggets, hardness and shear force of control formula was significantly higher than the others in fully fried products $(p<0.05)$, which it would be associated with the low moisture content. Changes in the textural properties of the fully-fried shrimp nuggets could be attributed to the physical and chemical changes occurred during the frying process, battering and breading in particular. Suderman [11] and Loewe [15] correlated textural changes with moisture loss, protein denaturation and starch gelatinization [5-9]. 
Citation: Haghshenas M, Hosseini H, Nayebzadeh K, Khanghah AM, Kakesh BS, et al. (2014) Production of Prebiotic Functional Shrimp Nuggets Using B-Glucan and Reduction of Oil Absorption by Carboxymethyl Cellulose: Impacts on Sensory and Physical Properties. J Aquac Res Development 5: 245 doi:10.4172/2155-9546.1000245

Page 4 of 5

\begin{tabular}{|l|l|l|l|l|l|l|l|}
\hline Formulations & Color & Taste & Texture & Smell & Juiciness & Chewiness & Overall acceptability \\
\hline Control & $6.9 \pm 0.78^{\mathrm{a}}$ & $7.0 \pm 0.78^{\mathrm{b}}$ & $6.8 \pm 0.81^{\mathrm{b}}$ & $7.0 \pm 0.78^{\mathrm{a}}$ & $6.2 \pm 0.84^{\mathrm{a}}$ & $6.5 \pm 0.78^{\mathrm{b}}$ & $6.6 \pm 0.73^{\mathrm{b}}$ \\
\hline CMC & $6.9 \pm 0.91^{\mathrm{a}}$ & $6.7 \pm 0.99^{\mathrm{b}}$ & $7.0 \pm 0.78^{\mathrm{b}}$ & $7.0 \pm 0.78^{\mathrm{a}}$ & $7.1 \pm 0.69^{\mathrm{c}}$ \\
\hline BG & $7.0 \pm 0.48^{\mathrm{a}}$ & $6.0 \pm 0.63^{\mathrm{a}}$ & $6.1 \pm 0.82^{\mathrm{a}}$ & $6.9 \pm 0.81^{\mathrm{a}}$ & $6.6 \pm 0.73^{\mathrm{b}}$ & $6.5 \pm 0.73^{\mathrm{b}}$ \\
\hline CMC+BG & $6.9 \pm 0.73^{\mathrm{a}}$ & $6.2 \pm 1.07^{\mathrm{a}}$ & $5.9 \pm 0.73^{\mathrm{a}}$ & $6.9 \pm 0.87^{\mathrm{a}}$ & $7.0 \pm 0.78^{\mathrm{c}}$ & $6.1 \pm 0.48^{\mathrm{a}}$ & $6.4 \pm 0.69^{\mathrm{b}}$ \\
\hline
\end{tabular}

$a, b, c$ Means in the same row with different superscript letters are significantly different $(p<0.05)$.

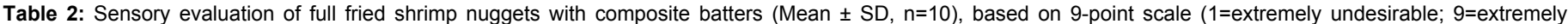
desirable).

\begin{tabular}{|l|l|l|l|l|}
\hline Parameters & Control & CMC & BG & CMC+BG \\
\hline Hardness $\left(\mathrm{N} / \mathrm{cm}^{2}\right)$ & $8.3 \pm 0.14^{\mathrm{c}}$ & $7.4 \pm 0.07^{\mathrm{b}}$ & $7.6 \pm 0.42^{\mathrm{b}}$ & $6.1 \pm 0.17^{\mathrm{a}}$ \\
\hline Springiness $(\mathrm{cm})$ & $1.21 \pm 0.03^{\mathrm{a}}$ & $1.26 \pm 0.02^{\mathrm{c}}$ & $1.23 \pm 0.03^{\mathrm{a}}$ & $1.5 \pm 0.02^{\mathrm{b}}$ \\
\hline Gumminess $\left(\mathrm{N} / \mathrm{cm}^{2}\right)$ & $4.31 \pm 0.10^{\mathrm{b}}$ & $5.69 \pm 0.09^{\mathrm{c}}$ & $4.25 \pm 0.19^{\mathrm{b}}$ & $4.02 \pm 0.18$ \\
\hline Chewiness (N/cm) & $5.21 \pm 0.07^{\mathrm{a}}$ & $7.16 \pm 0.03^{\mathrm{c}}$ & $5.22 \pm 0.17^{\mathrm{a}}$ & $6.03 \pm 0.05^{\mathrm{b}}$ \\
\hline Cohesiveness (ratio) & $0.52 \pm 0.02^{\mathrm{a}}$ & $0.77 \pm 0.02^{\mathrm{c}}$ & $0.56 \pm 0.02^{\mathrm{a}}$ & $0.66 \pm 0.02^{\mathrm{b}}$ \\
\hline Shear force (N) & $5.32 \pm 0.07^{\mathrm{c}}$ & $4.62 \pm 0.11^{\mathrm{b}}$ & $4.83 \pm 0.07^{\mathrm{b}}$ & $4.24 \pm 0.07^{\mathrm{a}}$ \\
\hline
\end{tabular}

$\mathrm{a}, \mathrm{b}, \mathrm{c}$ Means in the same row with different superscript letters are significantly different $(p<0.05)$.

Table 3: Effect of Carboxy methyl cellulose and $\beta$ - glucanon textural properties of par-410 fried shrimp nuggets.

\begin{tabular}{|l|l|l|l|l|}
\hline Parameters & Control & CMC & BG & CMC+BG \\
\hline Hardness $\left(\mathrm{N} / \mathrm{cm}^{2}\right)$ & $10.11 \pm 0.07^{\mathrm{d}}$ & $8.62 \pm 0.07$ & $8.93 \pm 0.17^{\mathrm{c}}$ & $8.15 \pm 0.14^{\mathrm{a}}$ \\
\hline Springiness $(\mathrm{cm})$ & $1.42 \pm 0.02$ & $1.28 \pm 0.02^{\mathrm{a}}$ & $1.42 \pm 0.02^{\mathrm{b}}$ & $2.14 \pm 0.02^{\mathrm{c}}$ \\
\hline Gumminess $\left(\mathrm{N} / \mathrm{cm}^{2}\right)$ & $4.44 \pm 0.07$ & $5.34 \pm 0.08^{\mathrm{c}}$ & $5.26 \pm 0.08^{\mathrm{c}}$ & $4.15 \pm 0.14^{\mathrm{a}}$ \\
\hline Chewiness $(\mathrm{N} / \mathrm{cm})$ & $6.30 \pm 0.02$ & $7.38 \pm 0.10^{\mathrm{b}}$ & $7.34 \pm 0.03^{\mathrm{b}}$ & $8.88 \pm 0.12^{\mathrm{c}}$ \\
\hline Cohesiveness (ratio) & $0.44 \pm 0.01$ & $0.62 \pm 0.01^{\mathrm{c}}$ & $0.59 \pm 0.02^{\mathrm{c}}$ & $0.51 \pm 0.02^{\mathrm{b}}$ \\
\hline Shear force (N) & $6.73 \pm 0.09$ & $5.77 \pm 0.04^{\mathrm{b}}$ & $5.85 \pm 0.03^{\mathrm{b}}$ & $5.40 \pm 0.10^{\mathrm{a}}$ \\
\hline
\end{tabular}

a,b,c Means in the same row with different superscript letters are significantly different $(p<0.05)$.

Table 4: Effect of Carboxy methyl cellulose and $\beta$-glucanon textural properties of full 427 fried shrimp nuggets.

\section{Sensory evaluation}

Generally, deep-frying causes fat to form an appealing and tasty surface on food [15]. When fat content is decreased or batter materials are altered, sensory characteristics might be affected. In our study, sensory evaluation showed no significant difference in color and smell among the formulations ( $\mathrm{p}>0.05)$. There was no significant difference between CMC and control formula except for the juiciness, which CMC formulation score was higher than control. Except for the juiciness and overall acceptability (Table 2), no significant difference was observed between BG and BG+CMC formulations ( $\mathrm{p}>0.05$ ). Sensory evaluation was carried out based on the hedonic scoring method on nugget samples to find the best organoleptic formula. The textural properties of the nuggets were evaluated using a texture analyzer and the Warner-Bratzler shear force of the fried shrimp nuggets was determined using an Instron universal testing machine. Based on the results, it is suggested prebiotic shrimp nuggets with less oil absorption and high sensory value can be prepared by adjusting the amount of hydrocolloids.

Moisture retention was increased by carboxymethyl cellulose to batter and resulted in softer and more cohesive shrimp nuggets. The use of $\beta$-glucan in shrimp nuggets was found to decrease substantially the hardness of the products with high moisture retention. Although $\mathrm{CMC}+\mathrm{BG}$ due to its low fat content was most favored formula, CMC sample led to better textural properties and higher sensory scores, significant reduction in absorbed oil and appropriate textural properties.

\section{Conclusions}

Industrial prebiotic shrimp nuggets using $\beta$-glucan with acceptable sensory and textural properties were produced as a functional sea food. In addition, application of carboxymethyl cellulose in shrimp nugget batter was effective to provide a low-calorie product by reducing the oil uptake during the frying process. Functional shrimp nuggets with desirable organoleptic properties offer a valuable alternative for consumers who are seeking low-fat fried products. This product has the potential to be manufactures and marketed as a functional calorie-reduced seafood product. More research is required to evaluate feasibility of large-scale production and the market niches of the formulated shrimp nuggets.

\section{References}

1. Ballard TS, Mallikarjunan $P$ (2006) The Effect of Edible Coatings and Pressure Frying Using Nitrogen Gas on the Quality of Breaded Fried Chicken Nuggets. Journal of Food Science 71: S259-S264.

2. Balaban MO (2000) Thermal Processing Effects on the Textural Attributes of Previously Frozen Shrimp. Journal of Aquatic Food Product Technology 9: 6184.

3. Durance TD (1999) Physical and Sensory Properties of Vacuum Microwave Dehydrated Shrimp. Journal of Aquatic Food Product Technology 8: 41-53.

4. Luzuriaga DA, Balaban MO, Hasan R, Teixeira AA (1997) A New Device for Measuring Texture Changes in Raw White Shrimp Stored on Ice. Journal of Aquatic Food Product Technology 6: 5-28.

5. Nunak N, Schleining G (2011) Instrumental Textural Changes in Raw White Shrimp During Iced Storage. Journal of Aquatic Food Product Technology 20: 350-360.

6. Dehghan Nasiri F, Mohebbi M, Tabatabaee Yazdi F, Haddad Khodaparas MH (2011) Kinetic Modeling of Mass Transfer During Deep Fat Frying of Shrimp Nuggets Prepared without a Pre-Frying Step. Food and Bioproducts Processing 89: 241-247.

7. Turan H, Kaya Y, Erdem ME (2011) Proximate Composition, Cholesterol, and Fatty Acid Content of Brown Shrimp (Crangon crangon L. 1758) from Sinop Region, Black Sea. Journal of Aquatic Food Product Technology 20: 100-107.

8. De Grandi Castro Freitas D, Berbari, SAG, Prati P, Fakhouri FM, Collares Queiroz FP, Vicente E (2009) Reducing Fat Uptake in Cassava Product During Deep-Fat Frying. Journal of Food Engineering 94: 390-394.

9. Sothornvit R (2011) Edible Coating and Post-Frying Centrifuge Step Effect on Quality of Vacuum-Fried Banana Chips. Journal of Food Engineering 107: 319 325.

10. Primo-Martín, C, Sanz T, Steringa DW, Salvador A, Fiszman SM, Van Vliet T (2010) Performance of Cellulose Derivatives in Deep-Fried Battered Snacks: Oil Barrier and Crispy Properties. Food Hydrocolloids 24: 702-708.

11. Singthong J, Thongkaew C (2009) Using Hydrocolloids to Decrease Oil Absorption in Banana Chips. LWT-Food Science and Technology 42: 11991203.

12. Yavari A, Heshmati A, Hamedi M, Haghbin S (2011) RETRACTED: VIS/NIR Hyper-Spectroscopy Technique for the Measurement of Moisture and Fat Contents of Breaded-Fried Chicken Nuggets. Food Chemistry 127: 645-650.

13. Chen HH, Kang HY, Chen SD (2008) The Effects of Ingredients and Water Content on The Rheological Properties of Batters and Physical Properties of Crusts in Fried Foods. Journal of Food Engineering 88: 45-54. 
Citation: Haghshenas M, Hosseini H, Nayebzadeh K, Khanghah AM, Kakesh BS, et al. (2014) Production of Prebiotic Functional Shrimp Nuggets Using B-Glucan and Reduction of Oil Absorption by Carboxymethyl Cellulose: Impacts on Sensory and Physical Properties. J Aquac Res Development 5: 245 doi:10.4172/2155-9546.1000245

Page 5 of 5

14. Chen SD, Chen HH, Chao YC, Lin RS (2009) Effect of Batter Formula on Qualities of Deep-Fat and Microwave Fried Fish Nuggets. Journal of Food Engineering 95: 359-364.

15. Holownia KI, Chinnan MS, Erickson MC, Mallikarjunan P (2000) Quality Evaluation of Edible Film-Coated Chicken Strips and Frying Oils. Journal of Food Science 65: 1087-1090.

16. Pinthus EJ, Weinberg P, Saguy IS (1993) Criterion for Oil Uptake during DeepFat Frying. Journal of Food Science 58: 204-205.

17. Williams R, Mittal GS (1999) Low-Fat Fried Foods with Edible Coatings: Modeling and Simulation. Journal of Food Science 64: 317-322.

18. Williams GOPPA (2000) Book of Hydrocolloids. Woodhead Publishing Limited and CRC Press LLC.

19. Akdeniz N, Sahin S, Sumnu G (2006) Functionality of Batters Containing Different Gums for Deep-Fat Frying of Carrot Slices. Journal of Food Engineering 75: 522-526.

20. Antonova I, Mallikarjunan P, Duncan SE (2003) Correlating Objective Measurements of Crispness in Breaded Fried Chicken Nuggets with Sensory Crispness. Journal of Food Science 68: 1308-1315.

21. Devadason, IP, Anjaneyulu ASR, Babji Y (2010) Effect of Different Binders on The Physico- Chemical, Textural, Histological, and Sensory Qualities of Retort Pouched Buffalo Meat Nuggets. Journal of Food Science 75: S31-S35.

22. Bouchon P (2009) Understanding Oil Absorption During Deep-Fat Frying Advances in Food and Nutrition Research.

23. Das AK, Anjaneyulu ASR, Gadekar YP, Singh RP, Pragati H (2008) Effect of Full-Fat Soy Paste and Textured Soy Granules on Quality and Shelf-Life of Goat Meat Nuggets in Frozen Storage. Meat Science 80: 607-614.

24. Martino M (2000) Edible Coatings From C ellulose Derivatives to Reduce Oil Uptake in Fried Products. Innovative Food Science Amp; Emerging Technologies 3: 391-397.

25. Morin LA, Temelli F, Mcmullen L (2002) Physical and Sensory Characteristics of Reduced-Fat Rea Fast Sausa Es Ormulated with Arle B-Glucan. Journal of Food Science 67: 2391-2396.

26. Prinyawiwatkul W, Mcwatters KH, Beuchat LR, Phillips RD (1997) Optimizing Acceptability of Chicken Nuggets Containing Fermented Cowpea and Peanut Flours. Journal of Food Science 62: 889-893.

27. Mälkki Y, Virtanen E (2001) Gastrointestinal Effects of Oat Bran and Oat Gum: A Review. LWT-Food Science and Technology 34: 337-347.

28. Gibson GGRM (1995) Dietary Modulation of the Human Colonic Microbiota Introducing the Concept of Prebiotics. Journal of Nutrition 125: 1401-1412.

29. Hooda SMJ, Vasanthan T, Ijlstra RT ( 2010) Dietary Purified Oat B-Glucan Reduces Peak Glucose Absorption and Portal Insulin Release in Portal-Vein Catheterized Grower Pigs. Livestock Science 134: 15- 17.

30. Mahan LK, SE-S (2007) Krause's Food and Nutrition Therapy, Food, Nutrition and Diet Therapy (Krause's) Series 12 Ed. Elsevier Health Sciences.

31. Venugopal V (2006) Seafood Processing Chapter 9 Coated Product, Food Science and Technology. Food Science and Technology: 259-280.

32. Braaten JTWP, Scott FW, Wolynetz MS, Lowe MK, Bradley-White P, Collins MW (1994) Oat B-Glucan Reduces Blood Cholesterol Concentration in Hypercholesterolemic Subjects. European Journal of Clinical Nutrition 48: 465474.

33. Lai H (2000) Fermentation of Resistance Starch Produces Propionate Reducing Serum and Hepatic Cholesterol in Rats. Journal of Nutrition 130: 1991-1995.

34. AOAC (2005) Official Methods of Analysis of the Association of Official Analytical Chemists.18th Ed. Gaithersburg MD: Author

35. Ngadi M, Li Y, Oluka S (2007) Quality Changes in Chicken Nuggets Fried in Oils with Different Degrees of Hydrogenatation. LWT-Food Science and Technology 40: 1784-1791.

36. Suderman DR, Cunningham FE (1983) Batter and Breading Technology. Ellis Horwood Limited.

37. Loewe R (1993) Role of Ingredients in Batter Systems. Cereal Foods World 38: 673-677. 